\title{
Beliefs and attitudes of Minnesota pharmacists regarding tobacco sales and smoking cessation counselling
}

\author{
Paul J Martinez, Judy Knapp, Thomas E Kottke
}

\begin{abstract}
Objectives-To determine pharmacists' perceived barriers to eliminating tobacco sales by pharmacies and to determine whether pharmacists are likely to increase their smoking cessation assistance activities in response to training programmes.
\end{abstract}

Design-Mail survey of 400 randomly selected pharmacists residing and registered to practice in Minnesota. The survey was conducted in January 1992; the completed survey response rate was $78 \%$. Results - Two-thirds of the respondents agreed with the statement that pharmacists should not sell tobacco products. However, $88 \%$ working in chain pharmacies and $43 \%$ working in independent pharmacies reported that tobacco was sold at their work site $(p<0.0001$ for difference in proportions). More than two-thirds who worked in a site that sold tobacco cited the manager's or owner's decision as the reason for continued tobacco product sales. Although $85 \%$ agreed that pharmacists should provide smoking cessation materials to their patients and $72 \%$ agreed that a pharmacist's role includes providing regular smoking cessation advice, only $27 \%$ said that they were likely to ask a patient if they smoked before filling a new prescription. The most frequently selected barriers to providing smoking cessation advice were fear of patient annoyance ( $58 \%$ agree), lack of time (43\% agree), and lack of sufficient knowledge to give advice (34\% agree); $72 \%$ denied interest in either training or certification in smoking cessation counselling.

Conclusions - Many pharmacists do not decide tobacco sales policy where they work; in these stores, tobacco elimination programmes will have to be directed at the owners rather than the pharmacists. Programmes to recruit pharmacists to be more active in smoking cessation will have to train them to deliver the services and demonstrate to them that their patients want these services.

(Tobacco Control 1993; 2: 306-310)
Introduction

Although pharmacies are part of the health services delivery system, they are also a major source of tobacco products for youth in the US. It has been estimated that $25 \%$ of cigarette purchases are made in pharmacies, ${ }^{1}$ and in a Massachusetts study, 13- to 16-yearold boys and girls were able to make a purchase in $81 \%$ of pharmacies where they asked for cigarettes. ${ }^{1}$ In a recent test in the Minneapolis -St Paul Metropolitan area, a 16-year-old decoy was able to purchase cigarettes in $85 \%$ of one chain pharmacy's stores. ${ }^{2}$ On average, the decoy was able to buy cigarettes in $78 \%$ of pharmacies. Sales of tobacco in pharmacies are in distinct conflict with the recommendations of the American Pharmaceutical Association, ${ }^{3}$ the National Association of Boards of Pharmacy, ${ }^{4}$ and state organisations like the Minnesota Board of Pharmacy, ${ }^{5}$ and the Minnesota Pharmacist Association (personal communication, William E Bond, executive director); all have resolutions encouraging pharmacies not to sell tobacco products.

In addition to eliminating tobacco sales by pharmacies, there is further potential to reduce the burden of tobacco on society by training pharmacists as smoking cessation counsellors and by developing smoking cessation devices and advice as products to replace lost profits when tobacco sales are eliminated. Pharmacists are trained health professionals that have been repeatedly rated by the public as having the highest honesty and ethical standards of all professionals ${ }^{6}$ further, pharmacists are far more accessible to the public than physicians. ${ }^{\text {? }}$

Before tobacco sales can be eliminated from pharmacies and pharmacists can be recruited to become smoking cessation counsellors, however, the knowledge, attitudes, and beliefs of pharmacists about eliminating tobacco sales from pharmacies and providing smoking cessation counselling must be defined. This paper presents the knowledge, attitudes and beliefs collected from a random sample of pharmacists practicing in Minnesota. Portions of the data from this survey have been published elsewhere. ${ }^{8}$

\section{Methods}

A task force of 10 pharmacists, selected to represent the community, hospital, managed care and academic pharmacy segments of the 
profession, was convened to develop the goals and objectives for the survey. Survey questions were then designed to address each objective identified by the task force. The majority of the questions were Likert-scaled items with five-point anchors. Except for eight demographic questions, the remaining questions were presented in a true/false or yes/no format. The draft survey was reviewed by the task force, revised by the investigators, and then pilot-tested with a group of practising pharmacists. The survey design and mailing procedures followed the recommendations of Dillman. ${ }^{9}$ The survey instrument is available from the authors on request.

After the names of pharmacists with an outof-state address were eliminated, Microsoft Excel was used to select randomly a sample of 400 pharmacists from the 4050 individuals registered with the Minnesota Board of Pharmacy to practice pharmacy in Minnesota as of October, 1991. This sample size was selected to balance the need to capture important

Table 1 Demographic characteristics of the survey respondents and pharmacists registered to practice in Minnesota $(M N)$ in 1990

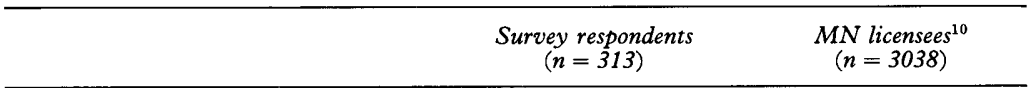

$-$

$=$

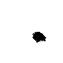

$$
\begin{aligned}
& \text { Age range (\%): } \\
& 21-29 \\
& 30-39 \\
& 40-49 \\
& 50-59 \\
& 60+
\end{aligned}
$$$$
\text { Sex (\% male) }
$$

Highest academic degree (\%)

BS

Pharm. Doctorate

Employment type (\%):

Employee Pharmacis

Pharmacy Manager

Pharmacy Owner

Self-employed

Other

Practice setting (\%):

Independent community

Chain

Hospital

Long-term care

Managed care

Industry

Other

Smoking status

$\%$ current smokers

$\%$ former smokers

N/A : not available

-

Table 2 Responses about the burden of tobacco and community attitudes towards pharmacies that sell tobacco products

\begin{tabular}{lccc}
\multicolumn{1}{c}{ Statement } & $\%$ Selecting response & \\
\hline & True & False \\
Second-hand smoke is dangerous to a non-smoker's & 99 & 1 & 4 \\
health & 96 & 4 & \\
$\begin{array}{l}\text { Smoking is the leading preventable cause of death in } \\
\text { the US }\end{array}$ & 96 & 21 & Don't know \\
$\begin{array}{l}\text { Smokeless tobacco products have been shown definitely } \\
\text { to increase the risk of cancer }\end{array}$ & 79 & No \\
$\begin{array}{l}\text { Nicotine addiction is as strong as heroin or cocaine } \\
\text { addiction }\end{array}$ & Yes & 5 & 55 \\
$\begin{array}{l}\text { Smoking cessation activities exist in the community in } \\
\text { which I practice }\end{array}$ & 75 & 31 & \\
$\begin{array}{l}\text { The community in which I practice would be more } \\
\text { likely to patronise pharmacies that do not sell tobacco } \\
\text { products }\end{array}$ & 14 & & \\
\hline
\end{tabular}

* "True" is the correst response in all four cases differences between independent and chain pharmacists and the need to keep the survey economically feasible.

The pharmacists were mailed the 46 -item questionnaire and a $\$ 1$ gratuity on 7 January 1992. A reminder post card was mailed one week later to those who had yet to respond. On 21 January 1992, a second questionnaire was mailed to those individuals who had not responded to the previous two mailings. A total of $321(81 \%)$ questionnaires were returned. Two questionnaires were returned because they were undeliverable and eight were returned uncompleted. The adjusted response rate was $78 \%(313 / 398)$. The data were analyzed with SPSSPC + . Differences in responses of employees, managers and owners about the reasons for continued tobacco sales were tested for statistical significance with the chi-square test.

\section{Results}

\section{DEMOGRAPHIC CHARACTERISTICS OF THE} RESPONDENTS

The demographic characteristics of the respondents were similar to the total population of pharmacists registered to practice in Minne$\operatorname{sota}^{10}$ (table 1). Half of the respondents were non-managerial employees, $21 \%$ were pharmacy managers, and $12 \%$ were pharmacy owners. One-third of the respondents worked in independent community pharmacies, $25 \%$ worked in chain pharmacies, and $25 \%$ worked in hospital pharmacies. Although one-third of the respondents had smoked in the past, only $6 \%$ of the respondents reported that they currently smoked.

REPORTED PREVALENCE OF TOBACCO SALES BY PHARMACIES

Overall, $39 \%$ of respondents indicated that their practice site sold tobacco products. While $88 \%$ of respondents who worked for chain pharmacies reported that tobacco products were sold at their practice site, only $43 \%$ of respondents working in independent community pharmacies reported that tobacco products were sold at their site $(\mathrm{p}<0.0001)$. Only $31 \%$ of independent community pharmacy owners indicated that they sold tobacco products. Few of the respondents who worked in hospitals, industry or other sites reported that tobacco products were sold at their place of employment.

\section{RESPONSES TO STATEMENTS ABOUT THE}

HAZARDS OF TOBACCO

For the most part, the respondents were able to select the correct answers about the health hazards associated with tobacco use (table 2). The majority of respondents reported that they were aware that smoking is the leading preventable cause of death in the US and that second-hand smoke is dangerous to a nonsmoker's health. They also appreciated the addictive nature of tobacco and the hazards of smokeless tobacco. Although three-quarters of 
Table 3 Responses to statements about a pharmacist's obligation to help reduce tobacco consumption

\begin{tabular}{|c|c|c|c|}
\hline \multirow[b]{2}{*}{ Statement } & \multicolumn{3}{|c|}{$\%$ Selecting response } \\
\hline & Agree & Neutral & Disagree \\
\hline $\begin{array}{l}\text { Pharmacies that sell tobacco products should make an } \\
\text { extra effort to reduce minors`^ access to cigarettes }\end{array}$ & 91 & 5 & 4 \\
\hline $\begin{array}{l}\text { A pharmacist has a responsibility to alert smokers to } \\
\text { potential smoking/drug interactions }\end{array}$ & 91 & 8 & 1 \\
\hline $\begin{array}{l}\text { The pharmaceutical industry should support smoking } \\
\text { prevention and cessation efforts }\end{array}$ & 86 & 10 & 4 \\
\hline $\begin{array}{l}\text { Pharmacies should provide up-to-date smoking cessation } \\
\text { information materials to their patients that smoke }\end{array}$ & 85 & 13 & 2 \\
\hline $\begin{array}{l}\text { A pharmacist's role should include being an active } \\
\text { member of a health team responsible for smoking } \\
\text { cessation }\end{array}$ & 79 & 17 & 4 \\
\hline $\begin{array}{l}\text { A pharmacist's role includes providing regular smoking } \\
\text { cessation advice to his/her patients that smoke }\end{array}$ & 72 & 22 & 6 \\
\hline $\begin{array}{l}\text { A pharmacist should strive regularly to provide } \\
\text { information regarding smoking cessation to smokers }\end{array}$ & 72 & 19 & 9 \\
\hline $\begin{array}{l}\text { A pharmacist should refrain from selling tobacco } \\
\text { products }\end{array}$ & 66 & 27 & 7 \\
\hline $\begin{array}{l}\text { A pharmacist's role includes being an active member of a } \\
\text { smoking cessation support network for patients } \\
\text { attempting to quit smoking }\end{array}$ & 65 & 26 & 10 \\
\hline $\begin{array}{l}\text { A pharmacist should regularly refer his/her patients who } \\
\text { smoke to smoking cessation programmes (ie, physicians, } \\
\text { clinics, etc) }\end{array}$ & 48 & 38 & 14 \\
\hline $\begin{array}{l}\text { A pharmacist should ask whether a patient smokes before } \\
\text { filling new prescriptions }\end{array}$ & 27 & 34 & 39 \\
\hline
\end{tabular}

${ }^{\star}$ minors $=$ persons under 18 years old

Table 4 Respondents' perceived reasons for the continued sale of tobacco products, expressed by pharmacists who work in pharmacies that sell tobacco products. Results are given as the percentage of respondents selecting reason by respondent status. Columns total greater than $100 \%$ because respondents were permitted to select multiple responses

\begin{tabular}{|c|c|c|c|c|}
\hline \multirow[b]{2}{*}{ Reason for continued sales } & \multicolumn{3}{|c|}{ Status of respondent } & \multirow[b]{2}{*}{ p-value } \\
\hline & $\begin{array}{l}\text { Employee } \\
(n=58)\end{array}$ & $\begin{array}{l}\text { Manager } \\
(n=36)\end{array}$ & $\begin{array}{l}\text { Owner } \\
(n=11)\end{array}$ & \\
\hline $\begin{array}{l}\text { Customers should be able to buy what } \\
\text { they want }\end{array}$ & 51 & 42 & 73 & NS* \\
\hline $\begin{array}{l}\text { People should be able to smoke if they } \\
\text { choose }\end{array}$ & 36 & 33 & 64 & NS \\
\hline Tobacco products are legal commodities & 43 & 28 & 46 & NS \\
\hline $\begin{array}{l}\text { Store will lose customers if tobacco } \\
\text { products are not available for sale }\end{array}$ & 50 & 42 & 46 & NS \\
\hline $\begin{array}{l}\text { Higher management (ie, manager/owner) } \\
\text { makes the decision }\end{array}$ & 81 & 81 & 0 & $0.001^{\&}$ \\
\hline Selling tobacco is company policy & 33 & 50 & 0 & $t$ \\
\hline $\begin{array}{l}\text { Revenue from cigarette sales is a } \\
\text { necessary addition to total sales }\end{array}$ & 26 & 28 & 9 & Ns \\
\hline
\end{tabular}

* $\mathrm{p}>0.05$ for all two-way comparisons among the three respondent categories

\& comparing owners to employees, and owners to managers

$\dagger \mathrm{p}=0.10$ comparing employees to managers, 0.05 comparing employees to owners, and

0.003 comparing managers to owners

Table 5 Respondents' perceived barriers to giving smoking cessation advice

\begin{tabular}{lccc}
\hline \multicolumn{1}{c}{ Statement } & \multicolumn{3}{c}{$\%$ Selecting response } \\
\cline { 2 - 4 } \cline { 4 - 4 } & Agree & Neutral & Disagree \\
\hline Patients would be annoyed & 58 & 23 & 21 \\
I lack the time required to give advice & 43 & 30 & 27 \\
I lack sufficient knowledge about smoking & 34 & 27 & 39 \\
prevention/cessation & 26 & 49 & 25 \\
I lack support from management & 24 & 25 & 51 \\
Patients would not expect it from me & 20 & 30 & 50 \\
Smoking prevention/cessation is a low priority issue for & & & \\
me & &
\end{tabular}

the respondents knew of smoking cessation activities in their community, the majority were unsure whether people from their communities were more likely to patronise pharmacies that do not sell tobacco products.

RESPONDENT ATTITUDES ABOUT PHARMACISTS' RESPONSIBILITIES

Almost all respondents agreed with the state- ment that pharmacies should make an extra effort to reduce minors' access to cigarettes, and almost all respondents agreed with the other general statements that indicated that the pharmacist has a role in tobacco control. Twothirds of the respondents agreed with the statement that a pharmacist should refrain from selling tobacco products (table 3).

However, their responses to statements about taking specific action were quite different. Only $48 \%$ agreed with the statement that a pharmacist should refer patients who smoked to smoking cessation programmes, and only $27 \%$ agreed with the statement that a pharmacist should ask whether a patient smokes before filling a new prescription.

\section{RESPONDENT BELIEFS ABOUT WHY TOBACCO IS} SOLD IN PHARMACIES

The prevailing opinion why tobacco continues to be sold in pharmacies tended to differ among employees, managers, and owners (table 4). While owners tended to cite customers' rights to buy what they want and to smoke if they choose, employees and managers most frequently cited higher management decisions as the reason that tobacco products were sold in their practice site. Only $9 \%$ of pharmacy owners selected the necessity of revenue from tobacco sales as a reason for continued tobacco sales.

\section{RESPONDENT INTEREST IN PROVIDING SMOKING} CESSATION ADVICE

Only $45 \%$ of the respondents expressed a desire for further information on smoking prevention; $72 \%$ neither expressed interest in training to give smoking cessation advice nor in being certified as a smoking cessation advisor. More than two-thirds of the respondents denied interest in receiving information about product or service alternatives to selling tobacco products.

The perception that advice would annoy the patient ( $58 \%$ selecting the statement) headed the list of perceived barriers to giving smoking cessation advice (table 5). Lack of time to give advice was selected by $43 \%$ of respondents, and lack of knowledge to intervene by $35 \%$. Only $26 \%$ selected lack of management support while $24 \%$ felt that the patient would not expect the advice. One in five respondents reported that giving smoking cessation advice was a low priority for them.

\section{Discussion}

This survey of 400 randomly selected pharmacists practicing in Minnesota reveals a number of important findings that must be taken into consideration if tobacco sales are to be eliminated from pharmacies and pharmacists are to be recruited as smoking cessation counsellors. First, we were pleasantly surprised to find that half of the pharmacists employed in independent community pharmacies reported that tobacco was not sold by their work site and more than two-thirds of 
independent community pharmacy owners said that they did not sell tobacco. On the other hand, almost $90 \%$ of pharmacists working in chain pharmacies reported that tobacco products were sold by their store. Over $80 \%$ of non-managerial employees and managers reported that the decision to sell tobacco was made at a level at which they lacked influence. While the respondents were able to identify the correct responses to statements about the hazards of tobacco use and believed in a general sense that pharmacists should be active in the tobacco control effort, only about half of the respondents felt that the pharmacist has an obligation to refer patients to smoking cessation programmes, and only about a quarter of the respondents agreed that the pharmacist has an obligation to ask new patients whether they smoke before prescriptions are filled. Few of the respondents expressed an interest in smoking cessation intervention training and more than half felt that their patients would be annoyed if they advised them to stop smoking.

The data reported here have the shortcoming of being generated by a self-report survey. Therefore, the reported proportions of pharmacies in which tobacco products are sold can be legitimately questioned. However, an on-site inspection programme in Ottawa, Ontario found that $42 \%$ of pharmacies did not sell tobacco in any form. ${ }^{11}$ All of the pharmacies that did not sell tobacco were independent pharmacies, and only $38 \%$ of independent pharmacies sold cigarettes.

The data reported here are also not the first to observe the conflict between the ideal of pharmacy as a health care profession and the reality that the pharmacist is frequently an employee without managerial authority in a business venture. Community pharmacists from Mississippi recently ranked the elimination of cigarette, pipe or cigar smoking second in importance among 25 suggested health promotion activities even though most of them worked in retail pharmacies that sold tobacco products. ${ }^{12}$ As in our study, however, studies in Georgia ${ }^{13}$ and elsewhere ${ }^{14,15}$ found that many pharmacists are not in full control of their work conditions. Most of those respondents, while working as staff pharmacists or managers at sites that sell tobacco products, also expressed the belief that pharmacists should not sell tobacco products. The decision to sell tobacco products in chain store pharmacies is often made by personnel at the corporate level who are located in another state. The continued, widespread disregard for laws that prohibit sales to minors ${ }^{2,16}$ suggests that only the elimination of all tobacco sales by pharmacies will eliminate sales to youth by these businesses. The data from the present survey suggest that, by enabling and activating the professional ideals that pharmacists already hold and have stated through their professional organisations, this goal is possible.

Owners of independent community pharmacies are obviously free to decide whether they will sell tobacco products, and those who continue to sell justify their actions by saying that adults have the right to use a legal (though deadly) product without interference. On the other hand, it is possible to use the majority of owners who do not sell tobacco to influence the behaviour of those who do. It is also possible to use the efforts of non-managerial employees in tobacco control effort. While these individuals cannot remove tobacco from pharmacy shelves without their employer's permission, they can attempt to persuade their employers to remove tobacco products from the store, or at least reduce the prominence with which tobacco products are displayed, and they can lobby their employers to eliminate point-of-purchase advertising. At a minimum, all pharmacists should comply with laws that prohibit selling tobacco products to minors, and all pharmacists can act as members of their community to direct opinion to support pharmacies that do not sell tobacco products and to direct public action against pharmacies that continue to sell tobacco products to youth.

Mobilising "insiders" has worked well with tobacco control programmes in Minnesota to create smoke-free hospitals, smoke-free schools, and smoke-free chemical dependency centres. In these efforts, we used a strategy of identifying and supporting members of the target group who believed as we did and were willing to advocate the changes to their peers. The support of peer advocates neutralises the "but you just don't understand our profession" argument. We see no reason why the same strategy cannot be effective in the effort to eliminate tobacco sales by pharmacies. From the tobacco control perspective, the goal has to be convincing pharmacy decision-makers that no longer selling tobacco will improve their professional and business standing in the communities they serve.

The more than $50 \%$ of community pharmacies in Minnesota and Ottawa ${ }^{11}$ that don't sell cigarettes provide us with an existing role model of tobacco-free pharmacies. We need to publicise these pharmacies; to define the process that these pharmacies went through when they elected to stop selling tobacco; and to provide descriptions of this process that other pharmacists can use when converting from tobacco sales to other products. Finally, we need to recruit activists from within this group of pharmacists who are willing to serve as opinion leaders in the profession at large and to serve as consultants to other pharmacists who are considering removing smoking products from their shelves.

The task of developing pharmacists into smoking cessation counsellors presents a different set of challenges. Pharmacists know of the health risks associated with smoking and are ideally positioned to become more active in health-promoting activities because the public holds pharmacists in high esteem. ${ }^{6}$ The public also has more contact with pharmacists than with any other health care professional; it has been estimated that the equivalent of the total population of the nation enters a community pharmacy in the US every 3.5 weeks. ${ }^{7}$

Smoking prevention and smoking cessation programmes need to address pharmacists' 
discomfort with advising their patients to stop smoking. It appears that pharmacists are comfortable asking about drug interactions, so the intervention could be focused on the interaction of tobacco and prescription drugs. It is feasible for managed care organisations to build appropriate questions into the databases they require pharmacists to collect when filling prescriptions. In addition to smoking status, these questions could include determining the patient's readiness to stop smoking ${ }^{17}$ and whether the patient wants help in stopping. The computer program could also generate drug-interaction advisories that can be given to the patient to emphasise the importance of quitting. Finally, our anecdotal experience suggests that customer inquiry about nicotine patches has increased many pharmacists' interest in offering this product as an over-thecounter device.

The effectiveness and feasibility of these strategies have yet to be demonstrated. However, the responses of the pharmacists in this survey suggest that tobacco sales can be eliminated from pharmacies if we are willing to tap into the professional idealism of pharmacists and provide them with the tools that will help them modify their practice environment. The elimination of tobacco from pharmacies will be one more step on the path to a smoke-free society.

Supported in part by an educational grant from the MarionMerrill Dow Corporation to the Minnesota Coalition for
Smoke-rree Society 2000 and by National Cancer Institute Grants CA 15083 and CA 57825 (Dr Kottke)

1 Brown LJ, DiFranza JR. Pharmacy promotion of tobacco use among children in Massachusetts. Am Pharm 1992 NS32: 421-4.

2 Sandell SD. Smoke screen award. Tobacco Control 1993; 2 56-7.

3 American Pharmaceutical Association. Code of ethics, approved August 1969, amended December 1975, revised fuly 1981. Washington, DC: American Pharmaceutical
Association. Association.

4 National Association of Boards of Pharmacy. Resolution No 88-6-92. A Smoke-free Society by the Year 2000. Park Ridge, Illinois: National Association of Boards of Pharmacy.

5 Minnesota Board of Pharmacy. Resolution passed at MN Board of Pharmacy Meeting, fanuary, 1992, St. Paul, Minnesota. St. Paul, Minnesota: Minnesota Board of Pharmacy.

6 Gallup poll shows pharmacists trusted, Minneapolis Star Tribune, August 9, 1992

7 Mayer F, Newton D. The pharmacist: gatekeeper of the community's health. Hosp Forum 1976; $11: 84-6$.

8 Martinez P. Cigarettes... to sell or not to sell. Minnesota Pharm 1992; 46: 13-8.

9 Dillman DA. Mail and telephone surveys: the total design method. New York: John Wiley \& Sons, 1978.

10 Hallstrom DE. Summary of manpower data for pharmacists licensed in Minnesota as of March 1, 1990. St. Paul, licensed in Minnesota as of March 1, 1990.
Minnesota: Minnesota Board of Pharmacy.

11 Moreau S, Taylor MC, Walker JD. Tobacco sales: Canadian pharmacies ignore professional recommendations. Tobacco Control 1992; 1 : 138.

12 Fincham JE, Smith MC. Pharmacists' views about health promotion practices. If Community Health 1988; 13 115-23.

13 Parish RC, Terrell JC. Georgia pharmacists' attitudes toward cigarettes and smokeless tobacco. Am Pharm 1989; NS29: 593-8.

14 Schroeder, SA, Showstack JA. Merchandising cigarettes in pharmacies: a San Francisco survey. Am $\mathcal{F}$ Public Health 1978; 68: 494-5.

15 Richards JW Jr, Blum A. Pharmacists who dispense cigarettes. $N Y$ State 7 Med 1978; 85:350-3.

16 Davis RM. Tobacco sales in pharmacies: mixing good drugs and bad drugs. Tobacco Control 1992; 1: 84-6.

17 Pallonen UE, Fava JL, Salonen JT, Prochaska JO. Readiness for smoking change among middle aged Finnish men. Addict Behav 1992; 17: 415-23.

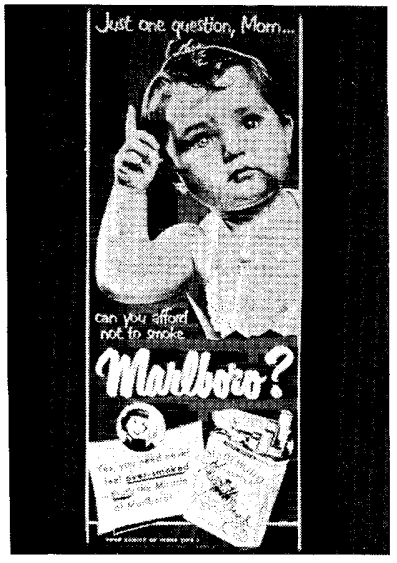

Marlboro advertisement, 1950 